\title{
Retention behavior of transition metals on a bifunctional ion-exchange column with oxalic acid as eluent
}

\author{
Xiaojing Ding, Shifen Mou* \\ Research Center for Eco-environmental Sciences, Chinese Academy of Sciences, P.O. Box 2871, Beijing 100085, China
}

\begin{abstract}
The common eluents used with a bifunctional ion-exchange column (IonPac CS5A) for separating transition metals are pyridine-2,6-dicarboxylic acid and oxalic acid (Ox). When Ox is used, cadmium and manganese co-elute. Although much research has been done to overcome the $\mathrm{Cd}^{2+}-\mathrm{Mn}^{2+}$ co-elution problem, the role of lithium hydroxide in separating the transition metals has received little attention. In this study, it is found that when the Ox concentration is higher than $35 \mathrm{~m} M$, $\mathrm{Cu}^{2+}$ elutes after $\mathrm{Pb}^{2+}$ and $\mathrm{Ox}$ plays a predominant role in the retention behavior of the seven metals. When Ox concentration is lower than $35 \mathrm{~m} M$ especially when its concentration $(25 \mathrm{~m} M)$ is half of the usually used standard concentration $(50 \mathrm{mM}), \mathrm{Cu}^{2+}$ elutes before $\mathrm{Pb}^{2+}$, and at the same time, $\mathrm{Mn}^{2+}$ and $\mathrm{Cd}^{2+}$ can also be baseline separated. Lithium hydroxide plays a predominant role in the separation of the metals separated by cation exchange. So, lithium hydroxide is used to adjust the $\mathrm{pH}$ of the eluent. The use of an isocratic elution (25 $\mathrm{m} M \mathrm{Ox} / \mathrm{LiOH} / 2 \mathrm{~m} M \mathrm{Na}_{2} \mathrm{SO}_{4}, \mathrm{pH}_{3.88}$ ) allows the separation of seven metals $\left(\mathrm{Cu}^{2+}, \mathrm{Pb}^{2+}, \mathrm{Co}^{2+}, \mathrm{Mn}^{2+}, \mathrm{Cd}^{2+}, \mathrm{Zn}^{2+}\right.$ and $\left.\mathrm{Ni}^{2+}\right)$ in a single run. The effects of inorganic modifiers such as $\mathrm{NaNO}_{3}, \mathrm{Na}_{2} \mathrm{SO}_{4}$ and $\mathrm{Na}_{4} \mathrm{P}_{2} \mathrm{O}_{7}$ on retention behavior of the metals are also investigated. (c) 2001 Elsevier Science B.V. All rights reserved.
\end{abstract}

Keywords: Retention behavior; Mobile phase composition; Transition metals; Oxalic acid

\section{Introduction}

At present, a bifunctional ion-exchange column (IonPac CS5A) is the most effective analytical column for separating transition metals. The common eluents advised by the column manufacturer are pyridine-2,6-dicarboxylic acid (PDCA) and oxalic acid (Ox). "Optimum" eluents are also recommended along with the column. However, these "optimum" conditions are indeed very good for the standard ions set for which the conditions were

*Corresponding author. Fax: +86-10-6292-3552.

E-mail address: shifenm@mail.rcess.ac.cn (S. Mou). developed, they are not appropriate if samples contain more or less ions [1]. For example, cadmium and manganese co-elute under the optimum $\mathrm{Ox}$ eluent conditions ( $80 \mathrm{~m} M$ Ox-100 $\mathrm{m} M$ tetramethylammonium hydroxide- $50 \mathrm{~m} M$ potassium hydroxide, $\mathrm{pH}=4.7 \pm 0.1$ [2] or $50 \mathrm{~m} M$ Ox $-95 \mathrm{~m} M$ lithium hydroxide [3]). The elution order is $\mathrm{Pb}^{2+}, \mathrm{Cu}^{2+}$, $\mathrm{Cd}^{2+}, \mathrm{Co}^{2+}, \mathrm{Zn}^{2+}$ and $\mathrm{Ni}^{2+}$. Therefore, some research dealing with the $\mathrm{Cd}^{2+}-\mathrm{Mn}^{2+}$ co-elution problem has been done and the retention behavior is discussed accordingly [4-6].

Cardellicchio et al. [4] used gradient elution (from $28 \mathrm{~m} M$ Ox-45 $\mathrm{m} M$ sodium chloride-116 $\mathrm{m} M$ sodium nitrate- $40 \mathrm{~m} M$ hydrochloric acid to $28 \mathrm{~m} M$ 
Ox-45 mM sodium chloride-265 $\mathrm{m} M$ sodium nitrate-40 $\mathrm{m} M$ hydrochloric acid in $15 \mathrm{~min}$ ) to obtain a satisfactory separation of nine metals in a single run. The elution order was $\mathrm{Cu}^{2+}, \mathrm{Cd}^{2+}, \mathrm{Ni}^{2+}$, $\mathrm{Zn}^{2+}, \mathrm{Co}^{2+}, \mathrm{Fe}^{2+}, \mathrm{Mn}^{2+}, \mathrm{Fe}^{3+}$ and $\mathrm{Pb}^{2+}$. Chloride is a weak ligand compared with oxalate and thus has little affect on the chromatography, but it plays a key role in the elution of iron, due probably to a mixed oxalate-chloride complexation of iron species. In general, $\mathrm{Pb}^{2+}$ is separated by cation exchange due to its weak complex with Ox. However, in this study, the retention of $\mathrm{Pb}^{2+}$ was thought to be primarily anion exchange, and the complex, $\mathrm{Pb}(\mathrm{Ox})_{2}^{2-}$ behaved as a polarizable anionic complex. For metals which forms stable complexes with Ox, mainly $\mathrm{Cu}^{2+}, \mathrm{Ni}^{2+}$, $\mathrm{Zn}^{2+}, \mathrm{Co}^{2+}$ and $\mathrm{Mn}^{2+}$, anion exchange dominates with elution order being inversely related to the stability constant. Lu et al. [5] described two kinds of gradient elution system. One allowed the same nine metals to be well separated in the same order in a single run (from $19.6 \mathrm{~m} M$ Ox-31.5 $\mathrm{m} M$ sodium chloride-80.5 $\mathrm{m} M$ sodium nitrate-28 $\mathrm{m} M$ hydrochloric acid to $28 \mathrm{~m} M$ Ox-45 $\mathrm{m} M$ sodium chloride$265 \mathrm{~m} M$ sodium nitrate $-40 \mathrm{~m} M$ hydrochloric acid in $23 \mathrm{~min}$ ); the separation selectivity was superior to that of Ref. [4]. The other allowed for the simultaneous separation and determination of seven transition metals (from $15 \mathrm{~m} M$ Ox-75 $\mathrm{m} M$ sodium chloride to $20 \mathrm{~m} M$ Ox-200 $\mathrm{m} M$ sodium chloride in 30 min). The elution order was $\mathrm{Cu}^{2+}, \mathrm{Ni}^{2+}, \mathrm{Zn}^{2+}$, $\mathrm{Cd}^{2+}, \mathrm{Co}^{2+}, \mathrm{Mn}^{2+}$ and $\mathrm{Pb}^{2+}$. Chloride ions could form complexes with some metals. Since all these metals had different conditional formation constants and distribution of species, they could be well separated by cation- and anion exchange components. Further detailed discussions were not given. Shawi and Dahl [6] exploited a gradient concentration of Ox and sodium chloride (12.5 $\mathrm{m} M$ Ox and $150 \mathrm{mM}$ ) to achieve the separation of seven transition metals in $15 \mathrm{~min}$. The elution order was $\mathrm{Cu}^{2+}$, $\mathrm{Cd}^{2+}, \mathrm{Ni}^{2+}, \mathrm{Zn}^{2+}, \mathrm{Co}^{2+}, \mathrm{Pb}^{2+}$ and $\mathrm{Mn}^{2+}$. They also found that the retention time was proportional mainly to the chloride ion concentration in the eluent, and thus chloride ions were introduced to improve the selectivity of the column. Increasing the chloride ion concentration caused a sharp decrease in the retention time of all seven cations. $\mathrm{Cu}^{2+}$, however, was eluted near the solvent front and variation of chloride concentration did not affect its retention time significantly, which can be explained by the strong complexes formed between $\mathrm{Cu}^{2+}$ and chloride ions. In contrast, increasing the $\mathrm{Ox}$ concentration while keeping the chloride ion concentration constant did not affect retention time. A gradient elution (from $35 \mathrm{~m} M$ Ox-0.15 $M \mathrm{NaCl}$ to $5 \mathrm{~m} M$ Ox-0.45 $M \mathrm{NaCl}$ in $15 \mathrm{~min}$ ) was also required to elute the retained $\mathrm{Fe}^{3+}$ on the column by decreasing the $\mathrm{Ox}$ concentration and increasing the chloride ion concentration.

The above-mentioned methods all added auxiliary ligand-chloride ions to the Ox eluent to help elute the transition metals and at the same time to solve the $\mathrm{Cd}^{2+}-\mathrm{Mn}^{2+}$ co-elution problem. In addition, it is obvious that decreasing the Ox concentration and increasing the chloride ion concentration accordingly is very advantageous for the separation of transition metals. When the Ox concentration is reduced to a certain extent, the auxiliary complexing effect of the chloride ions plays a key role in separating transition metals and solving the $\mathrm{Cd}^{2+}-\mathrm{Mn}^{2+}$ co-elution problem. Since the composition of the eluent provide a great flexibility for manipulating an analyte retention in order to achieve the desired separation [7] and the above-mentioned methods all concentrated on this aspect, So, there may be another simple way to solve the $\mathrm{Cd}^{2+}-\mathrm{Mn}^{2+}$ co-elution problem.

Based on our previous work in this laboratory [5,8-10], our present work still uses $\mathrm{Ox}$ as the eluent and we try to solve the $\mathrm{Cd}^{2+}-\mathrm{Mn}^{2+}$ co-elution problem in an isocratic elution when the weak ligand-chloride ions are not added to the eluent. Another purpose of the present work is to present a more detailed study of the key parameters affecting the retention behavior of transition metals with the chromatographic system chosen in a mixed bed exchanger (IonPac CS5A). It is found that when the Ox concentration $(25 \mathrm{mM})$ is half of the usually used standard concentration $(50 \mathrm{mM})$, lithium hydroxide plays a key role in separating the transition metals. The use of an isocratic elution $(25 \mathrm{~m} M$ Ox-LiOH-2 $\mathrm{mM} \mathrm{Na} \mathrm{SO}_{4}, \mathrm{pH} 3.88$ ) allows for the good separation of seven transition metals in a single run. The elution order is $\mathrm{Cu}^{2+}, \mathrm{Pb}^{2+}, \mathrm{Co}^{2+}, \mathrm{Mn}^{2+}, \mathrm{Cd}^{2+}$, $\mathrm{Zn}^{2+}$ and $\mathrm{Ni}^{2+}$. Several inorganic modifiers such as $\mathrm{NaNO}_{3}, \mathrm{Na}_{2} \mathrm{SO}_{4}$ and $\mathrm{Na}_{4} \mathrm{P}_{2} \mathrm{O}_{7}$ are used to evaluate the retention behavior of transition metals and then 
the interesting phenomena will be explained from these results.

\section{Experiment}

\subsection{Instrumentation}

Chromatographic analysis is performed on a metal-free Dionex-4000i ion chromatography (Dionex, Sunnyvale, CA, USA) system, which includes one advanced gradient pump (AGP), one pneumatic controller for post-column reagent addition (RDM), one eluent degas module (EDM) and a VDM-2 variable-wavelength absorbance detector at $565 \mathrm{~nm}$. A Dionex IonPac CG5A guard column $(50 \times 4 \mathrm{~mm}$ I.D.) and an IonPac CS5A analytical column $(250 \times 4 \mathrm{~mm}$ I.D., $9 \mu \mathrm{m}$ bead diameter, ethylvinylbenzene-functionalized with both quaternary ammonium and sulfonate functional groups) are used to separate the transition metals. A $118 \mu \mathrm{l}$ injection loop is used. The experiment is made at room temperature $\left(26 \pm 2^{\circ} \mathrm{C}\right)$.

Data collection and the operation of all components in the system are controlled by Dionex AI-450 chromatographic software interfaced via an ACI-2 advanced computer interface to a 80486 based computer.

\subsection{Reagents and standards}

All reagents are analytical grade unless specified otherwise. All solutions are prepared with deionized water throughout. Lithium hydroxide monohydrate, oxalic acid, sodium hydroxide, sodium sulfate anhydrous, aminoacetic acid, 2-(5-bromo-2-pyridyl)azo-5-diethylaminophenol (5-Br-PADAP), ethanol (Peking Chemical works, Peking, China), sodium chloride (Peking Shuanghuan Reagent Factory, Peking, China), sodium nitrate, (Peking Hongxing Chemical Works, Peking, China), sodium pyrophosphate (Peking Xingjin Chemical works, Peking, China), Triton X-100 (Carl Roth, Karlsruhe, Germany).

Post-column reagent: $0.3 \mathrm{~m} M \quad$ 5-Br-PADAP$0.95 \%(\mathrm{w} / \mathrm{v})$ Triton X-100-0.066 $M$ aminoacetic acid-0.067 $M$ sodium hydroxide- $0.12 M \mathrm{NaCl}(\mathrm{pH}$ 12). Post-column reagent flow-rate: $0.45 \mathrm{ml} / \mathrm{min}$.
Working standard solutions are prepared by serial dilution of stock standard solutions of each metal containing $1000 \mathrm{mg} \mathrm{l}^{-1}$ (National Research Center for Certified Reference Materials, Peking, China). All standards and samples are stored in acid washed (10\% nitric acid) polyethylene bottles.

\section{Results and discussion}

\subsection{Effect of Ox concentration on retention behavior of transition metals}

Ox concentration controls the column selectivity and contributes to peak efficiency. So, first of all, the dependence of retention behavior of transition metals on Ox concentration at constant $\mathrm{pH}$ (3.84, adjusted by $\mathrm{LiOH}$ ) and inorganic modifier concentration (3 $\mathrm{mM} \mathrm{NaNO}$ ) is examined. It was found that reducing the concentration of $\mathrm{Ox}$ is favorable for the separation of transition metals, especially $\mathrm{Cd}^{2+}$ and $\mathrm{Mn}^{2+}$ can be baseline separated when Ox concentration is lower than $28 \mathrm{~m} M$. However, since the present work will not use the auxiliary ligand-chloride ions, Ox concentration cannot be too low to elute the transition metals. When the Ox concentration is reduced to $21 \mathrm{~m} M$, the eluent power of $\mathrm{Ox}$ becomes so weak that $\mathrm{Ni}^{2+}$ cannot be eluted from the column. The increase of Ox concentration up to $30 \mathrm{~m} M$ would worsen the resolution. So, $25 \mathrm{~m} M$, which happens to be half of the recommended standard concentration $(50 \mathrm{mM})$, is chosen as the optimum Ox concentration.

Ox is a moderate complexing reagent. In general, complexing of metal ion by oxalate can be considered as a two-step reaction [11]:

$$
\begin{aligned}
& \mathrm{M}^{2+}+\mathrm{Ox}^{2-} \Leftrightarrow \mathrm{MOx} \\
& \mathrm{MOx}+\mathrm{Ox}^{2-} \Leftrightarrow \mathrm{MOx}_{2}^{2-}
\end{aligned}
$$

If oxalate is in considerable excess over the metal ion concentration, the species $\mathrm{MOx}_{2}^{2-}$ will be favored and the equilibrium may be written:

$\mathrm{M}^{2+}+2 \mathrm{Ox}^{2-} \Leftrightarrow \mathrm{MOx}_{2}^{2-}$

Then, the retention behavior mainly depends on the total complexation constant for reaction (3). $\mathrm{Pb}^{2+}$, 
$\mathrm{Cd}^{2+}$ and $\mathrm{Mn}^{2+}$ form relatively weak complexes with oxalate $\left(\log \beta_{\mathrm{Pb}-\mathrm{Ox}}=5.8, \log \beta_{\mathrm{Cd}-\mathrm{Ox}}=5.8, \log \right.$ $\beta_{\mathrm{Mn}-\mathrm{Ox}}=4.4$ [5]) and, as a general rule, are separated by cation exchange. $\mathrm{Cu}^{2+}, \mathrm{Co}^{2+}, \mathrm{Zn}^{2+}$ and $\mathrm{Ni}^{2+}$ form relatively stable complexes with oxalate (log $\beta_{\mathrm{Cu}-\mathrm{Ox}}=9.2, \log \beta_{\mathrm{Co-Ox}}=5.6, \log \beta_{\mathrm{Zn}-\mathrm{Ox}}=6.4, \log$ $\left.\beta_{\mathrm{Ni}-\mathrm{Ox}}=7.6[6]\right)$ and are separated by anion exchange.

\subsection{Effect of inorganic modifier on capacity factor of transition metals}

Now that Ox concentration was reduced to 25 $\mathrm{m} M$, some inorganic anions that did not have complexing abilities should be used to help elute the transition metals separated by anion exchange. In order to study the retention behavior of transition metals on IonPac CS5A column, $\mathrm{NO}_{3}^{-}, \mathrm{SO}_{4}^{2-}$ with no complexing ability and $\mathrm{P}_{2} \mathrm{O}_{7}^{4-}$ with complexing ability were added to the eluent, respectively.

As can be seen from Fig. 1a-c, increasing all the three inorganic modifiers' concentrations caused a sharp decrease in the capacity factor of the seven metals, which illustrated that the addition of inorganic modifiers increases the Ox eluent power. $\mathrm{Cu}^{2+}$, however, was eluted first and variation of the above inorganic modifier's concentration did not affect its retention time significantly, which can be explained by the strong complexes formed between $\mathrm{Cu}^{2+}$ and $\mathrm{Ox}\left[\mathrm{Cu}(\mathrm{Ox})_{2}^{2-}\right] . \mathrm{NO}_{3}^{-}$as monovalent eluting anion is the weakest to elute the anionic complexes. The optimum concentration of $\mathrm{NO}_{3}^{-}$was $3 \mathrm{~m} M$ as showed in Fig. 1a. $\mathrm{SO}_{4}^{2-}$, as divalent eluting anion, is stronger than $\mathrm{NO}_{3}^{-}$to elute the anionic complexes. The optimum concentration of $\mathrm{SO}_{4}^{2-}$ was $2 \mathrm{mM}$ as illustrated in Fig. 1b. What is different with $\mathrm{NO}_{3}^{-}$and $\mathrm{SO}_{4}^{2-}$ is that $\mathrm{P}_{2} \mathrm{O}_{7}^{4-}$ has a complexing ability with transition metals. When the $\mathrm{pH}$ of the eluent is 3.80 , the mainly existed form is $\mathrm{H}_{2} \mathrm{P}_{2} \mathrm{O}_{7}^{2-}$, for $\mathrm{H}_{4} \mathrm{P}_{2} \mathrm{O}_{7}$ has four prototropic dissociations: $\mathrm{p} K_{\mathrm{a} 1}=1.52, \mathrm{p} K_{\mathrm{a} 2}=$ 2.36, $\mathrm{p} K_{\mathrm{a} 3}=6.6$ and $\mathrm{p} K_{\mathrm{a} 4}=9.25 . \mathrm{Pb}^{2+}$ can form stable complex with $\mathrm{P}_{2} \mathrm{O}_{7}^{4-}(\beta=10.15)$ when $\mathrm{pH}$ is high enough, which will prevent $\mathrm{Pb}^{2+}$ from complexing with the post-column reagent-5-Br-PADAP, and thus its detection sensitivity will reduced. So, the concentration of $\mathrm{Na}_{4} \mathrm{P}_{2} \mathrm{O}_{7}$ in the eluent should not be too high. The optimum concentration is $1 \mathrm{mM}$.

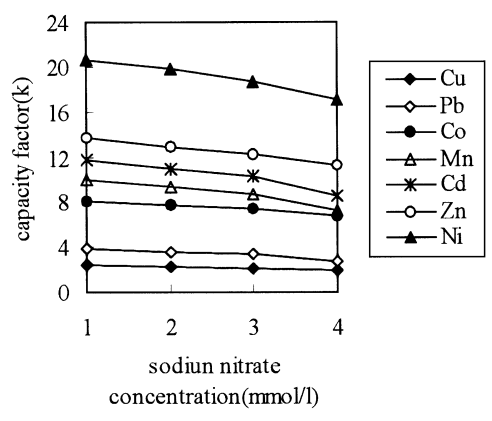

(a)

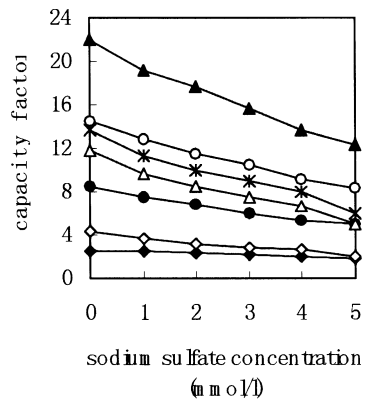

(b)

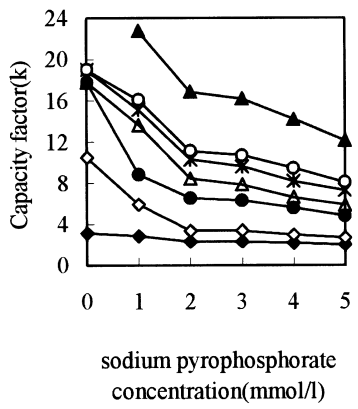

(c)
Fig. 1. (a) $\mathrm{Ox}-\mathrm{NaNO}_{3}-\mathrm{LiOH}$ eluent system; the effect of sodium nitrate concentration on capacity factors of metals. $25 \mathrm{mM}$ Ox and $\mathrm{pH} 3.96$ remain unchanged. Eluent flow-rate: $1 \mathrm{ml} / \mathrm{min}$. Loop volume: $118 \mu$ l. (b) $\mathrm{Ox}-\mathrm{Na}_{2} \mathrm{SO}_{4}-\mathrm{LiOH}$ eluent system; the effect of sodium sulfate concentration on capacity factors of metals. 25 $\mathrm{m} M$ Ox and $\mathrm{pH} 3.88$ remain unchanged. The other conditions are the same as (a). (c) $\mathrm{Ox}-\mathrm{Na}_{4} \mathrm{P}_{2} \mathrm{O}_{7}-\mathrm{LiOH}$ eluent system; the effect of sodium pyrophosphorate concentration on capacity factors of metals. $25 \mathrm{~m} M$ Ox and $\mathrm{pH} 3.80$ remain unchanged. The other conditions are the same as (a).

$\mathrm{NaNO}_{3}, \mathrm{Na}_{2} \mathrm{SO}_{4}$ and $\mathrm{Na}_{4} \mathrm{P}_{2} \mathrm{O}_{7}$ in the eluent could reduce the tailing of the $\mathrm{Pb}^{2+}$ and $\mathrm{Ni}^{2+}$ peaks and improve the peak shapes. However, $\mathrm{Na}_{2} \mathrm{SO}_{4}$ was found to be the best. All the above three kinds of eluent system can well separate the seven transition metals in an isocratic elution under each optimium eluent conditions as illustrated in Fig. 2a, b and c, respectively. In consideration of peak shape, run time and detection sensitivity, the $25 \mathrm{~m} M$ Ox-2 $\mathrm{m} M$ $\mathrm{Na}_{2} \mathrm{SO}_{4}-\mathrm{LiOH}$ ( $\mathrm{pH}$ 3.88) eluent system was found to be the optimum and was chosen for the following experiments.

Since $\mathrm{Fe}^{3+}$ and $\mathrm{Al}^{3+}$ often existed in the eluent and could not be eluted from the column due to their 

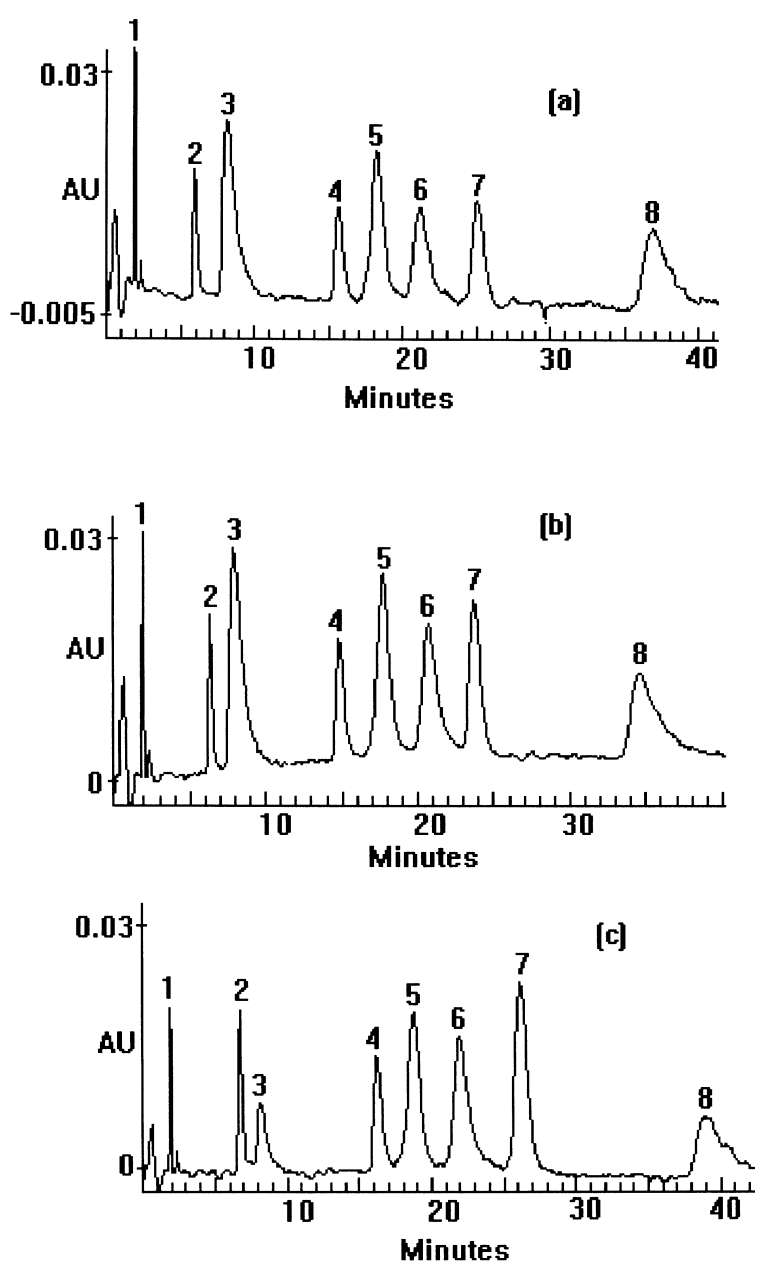

Fig. 2. Standard chromatograms of seven transition metals under three different kinds of optimum eluent system. (a) $25 \mathrm{mM}$ Ox-3 $\mathrm{m} M \mathrm{NaNO}_{3}-\mathrm{LiOH}$, pH 3.96. (b) $25 \mathrm{~m} M$ Ox-2 $\mathrm{m} M \mathrm{Na}_{2} \mathrm{SO}_{4}-$ LiOH, pH 3.88. (c) $25 \mathrm{~m} M$ Ox-1 $\mathrm{m} M \mathrm{Na}_{4} \mathrm{P}_{2} \mathrm{O}_{7}-\mathrm{LiOH}, \mathrm{pH} 3.80$. Peaks: $1=$ unknown, $2=\mathrm{Cu}^{2+}(0.1 \mathrm{mg} / \mathrm{l}), 3=\mathrm{Pb}^{2+}(2 \mathrm{mg} / \mathrm{l})$ $4=\mathrm{Co}^{2+}(0.2 \mathrm{mg} / \mathrm{l}), 5=\mathrm{Mn}^{2+}(0.3 \mathrm{mg} / \mathrm{l}), 6=\mathrm{Cd}^{2+}(0.5 \mathrm{mg} / \mathrm{l})$, $7=\mathrm{Zn}^{2+}(0.2 \mathrm{mg} / \mathrm{l}), 8=\mathrm{Ni}^{2+}(2 \mathrm{mg} / \mathrm{l})$. The other chromatographic conditions are the same as in Fig. 1a.

anionic form $\mathrm{Fe}(\mathrm{Ox})_{3}^{3-}$ and $\mathrm{Al}(\mathrm{Ox})_{3}^{3-}$ strongly retained by the column. So, a very low variation gradually in the retention time of the seven metals was observed after a few analyses. The column should be periodically cleaned by a eluent containing $25 \mathrm{~m} M$ PDCA-16.6 $\mathrm{m} M$ sodium sulfate-lithium hydroxide ( $\mathrm{pH} 4.9)$ in order to prevent excessive accumulation of iron and aluminum from eluent.

$2 \mathrm{~m} M \mathrm{NaNO}_{3}, 2 \mathrm{~m} M \mathrm{Na}_{2} \mathrm{SO}_{4}$ and $2 \mathrm{~m} M$
$\mathrm{Na}_{4} \mathrm{P}_{2} \mathrm{O}_{7}$ were added to the eluent while $25 \mathrm{~m} M$ Ox and $\mathrm{pH} 3.90$ (adjusted with $\mathrm{LiOH}$ ) kept constant. It was found that the retention times of $\mathrm{Cu}^{2+}$ and $\mathrm{Pb}^{2+}$ did not vary significantly which further illustrated that $\mathrm{Pb}^{2+}$ was separated by cation exchange while $\mathrm{Cu}^{2+}$ was separated by anion exchange due to the strong complex formed between $\mathrm{Cu}^{2+}$ and $\mathrm{Ox}$.

\subsection{Effect of lithium hydroxide on capacity factor of transition metals}

Among the alkli metals, $\mathrm{Li}^{+}$is the weakest ion to retain on the cation exchange resin with low capacity. When it is used as the eluting ion, the capacity of the transition metals can get the highest. So, the effect of lithium hydroxide and sodium hydroxide on retention behavior of transition metals should be different when transition metals are separated by cation exchange. From Section $3.2, \mathrm{~Pb}^{2+}$ is known to be separated by cation exchange while $\mathrm{Cu}^{2+}$ is separated by anion exchange and the $\mathrm{Cu}^{2+}$ peak elutes before the $\mathrm{Pb}^{2+}$ peak. Fig. 3a shows an interesting phenomenon: when the Ox concentration is lower than $35 \mathrm{mM}, \mathrm{Cu}^{2+}$ will elute before $\mathrm{Pb}^{2+}$; when the Ox concentration exceeds $35 \mathrm{mM}, \mathrm{Cu}^{2+}$ will elute after $\mathrm{Pb}^{2+}$. However, this phenomenon is not observed when sodium hydroxide is used to adjust the $\mathrm{pH}$ of the eluent as shown in Fig. 3b. It is obvious that both $\mathrm{Ox}$ concentration and $\mathrm{Li}^{+}$ions play a key role in the separation of $\mathrm{Cu}^{2+}$ and $\mathrm{Pb}^{2+}$ especially in the elution order of $\mathrm{Cu}^{2+}$ and $\mathrm{Pb}^{2+}$. Ox plays a predominant role in the retention behavior of the seven metals when its concentration is higher

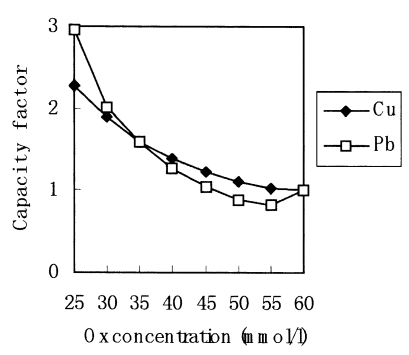

(a)

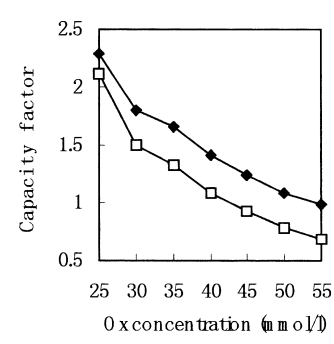

(b)
Fig. 3. Effect of Ox concentration on capacity factors of $\mathrm{Cu}^{2+}$ and $\mathrm{Pb}^{2+} .2 \mathrm{mM} \mathrm{Na} \mathrm{SO}_{4}$ and $\mathrm{pH} 3.88$ remain unchanged. (a) $\mathrm{LiOH}$ is used to adjust the $\mathrm{pH}$ of the eluent. (b) $\mathrm{NaOH}$ is used to adjust the $\mathrm{pH}$ of the eluent. 
than $35 \mathrm{~m} M$, however, it has been demonstrated in Section 3.1 that increasing the $\mathrm{Ox}$ concentration could worsen the separation of $\mathrm{Cu}^{2+}$ and $\mathrm{Pb}^{2+}$; $\mathrm{Mn}^{2+}$ and $\mathrm{Cd}^{2+}$. When Ox concentration is lower than $35 \mathrm{~m} M$ especially when its concentration is 25 $\mathrm{m} M$, things would be different. $\mathrm{Li}^{+}$ions play a predominant role in the retention behavior of the metals separated by cation exchange. So, the retention behavior of $\mathrm{Pb}^{2+}$ can be significantly influenced while the retention behavior of $\mathrm{Cu}^{2+}$ (separated by anion exchange) was not influenced at all as showed in Fig. 3a and b, respectively. As a result, $\mathrm{Cu}^{2+}$ and $\mathrm{Pb}^{2+}$ can be well separated with the preferred elution order by using $\mathrm{LiOH}$ to adjust the eluent $\mathrm{pH}$.

Our previous work [9] has tested that under the PDCA eluent conditions, $\mathrm{Pb}^{2+}$ elutes first and is close to the negative peak of water, which limits the volume of a loop used in real sample analysis. The use of a large loop can lower the detection limits. Unfortunately, when the loop exceeded $200 \mu$, only the $\mathrm{Pb}^{2+}$ peak fell into the large negative peak of water, and thus influencing the quantitative analysis of $\mathrm{Pb}^{2+}$. However, $\mathrm{Pb}^{2+}$ is of considerable concern in our daily life and its accurate determination is important from an ecotoxicological point of view. $\mathrm{So}, \mathrm{Pb}^{2+}$ being eluted in a short time and being far away from the negative peak of water is always desired for the quantitative analysis of $\mathrm{Pb}^{2+}$. The present established optimum eluent system (25 $\mathrm{m} M$ Ox-2 mM Na $\mathrm{SO}_{4}-\mathrm{LiOH}(\mathrm{pH} 3.88)$ ) could well meet this demand.

\subsection{Effect of eluent $p H$ on capacity factors of transition metals}

Because weak organic acids are effective chelating agents only when ionized, eluent $\mathrm{pH}$ has a dramatic effect on the separation and retention of the metals. Ox has two dissociation constants: $\mathrm{p} K_{\mathrm{a} 1}=1.0$ and $\mathrm{p} K_{\mathrm{a} 2}=3.8$, respectively. The eluent $\mathrm{pH}$ must exceed 3.8 to ensure the formation of metal-oxalate, which could be retained on the anion exchange site on the IonPac CS5A column. With an increase in $\mathrm{pH}$, the eluting ability of $\mathrm{Ox}$ increases and thus results in a decrease of the capacity factors. However, $\mathrm{Cu}^{2+}$ $\mathrm{Pb}^{2+}$ and $\mathrm{Co}^{2+}-\mathrm{Mn}^{2+}$ will not be baseline separated. As Fig. 4 shows, the best separation of the

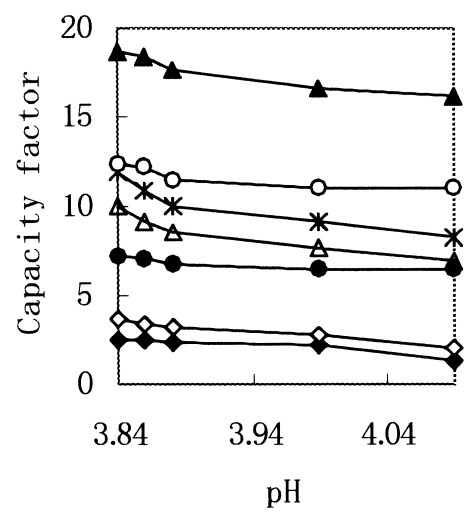

Fig. 4. Effect of $\mathrm{pH}$ on capacity factors of metals, $25 \mathrm{mM} \mathrm{Ox}-2$ $\mathrm{mM} \mathrm{Na} \mathrm{SO}_{4}$ remains unchanged. The other conditions are the same as in Fig. 1a.

metals can be achieved using an eluent of $\mathrm{pH} 3.88$. The separation under the optimum conditions is shown in Fig. $2 b$.

\section{Conclusions}

Ox eluent can offer good selectivity and resolution. Different additives to the eluent can make different interactions between the eluent ions and the stationary phase, and thus result in different elution orders of transition metals. The $\mathrm{Cd}^{2+}-\mathrm{Mn}^{2+}$ coelution problem is solved accordingly. The retention behavior of transition metals on IonPac CS5A column is greatly dependent on the eluent composition. Under the present newly established eluent system$25 \mathrm{~m} M$ Ox-2 $\mathrm{m} M \mathrm{Na}_{2} \mathrm{SO}_{4}-\mathrm{LiOH}(\mathrm{pH} 3.88$ ), the $\mathrm{Cd}^{2+}-\mathrm{Mn}^{2+}$ co-elution problem is overcome.

\section{References}

[1] C.A. Lucy, J. Chromatogr. A 739 (1996) 3.

[2] Installation Instructions and Troubleshooting Guide for the IonPac CG5A Guard Column and IonPac CS5A Analytical Column, Dionex, Sunnyvale, CA, 23 February 1996.

[3] J. Riviello, A. Woodruff, C. Pohl, IonPac CS5A Column Training Manual, Dionex, Sunnyvale, CA, March 1996.

[4] N. Cardellicchio, S. Cavalli, P. Ragone, J.M. Riviello, J. Chromatogr. A 847 (1999) 251.

[5] H.T. Lu, S.F. Mou, J.M. Riviello, J. Chromatogr. A 857 (1999) 343. 
[6] A.W.A. Shawi, R. Dahl, Anal. Chim. Acta 391 (1999) 35.

[7] Safni, T. Takeuchi, T. Miwa, Y. Hashimoto, H. Moriyama, J. Chromatogr. A 850 (1999) 65.

[8] Y.W. Hou, S.F. Mou, Y. Yan, F. Liu, H.T. Wang, K.A. Li, S.Y. Tong, Chin. J. Anal. Chem. 25 (11) (1997) 1241.

[9] X.J. Ding, S.F. Mou, K.N. Liu, A. Siriraks, J. Riviello, Anal. Chim. Acta 407 (2000) 319.
[10] X.J. Ding, S.F. Mou, K.N. Liu, Y. Yan, J. Chromatogr. A 883 (2000) 127.

[11] H. Small, Ion Chromatography, Plenum Press, New York and London, p. 77. 